\title{
Mortality of Birds of Prey Following Field Application of Granular Carbofuran: A Case Study
}

\author{
D. R. Dietrich ${ }^{1,4}$, P. Schmid ${ }^{1}$, U. Zweifel ${ }^{1}$, Ch. Schlatter ${ }^{1}$, S. Jenni-Eiermann ${ }^{2}$, H. Bachmann ${ }^{2}$, U. Bühler ${ }^{3}$, \\ N. Zbinden ${ }^{2}$ \\ ${ }^{1}$ Institute of Toxicology, Swiss Federal Institute of Technology and University of Zurich, CH-8603 Schwerzenbach, Switzerland \\ 2 Swiss Ornithological Institute, CH-6204 Sempach, Switzerland \\ 3 Department of Forestry of the Canton Grison, CH-7013 Domat/Ems, Switzerland \\ ${ }^{4}$ Department of Environmental and Occupational Health, University of Pittsburgh, Pittsburgh, PA 15238, USA
}

\begin{abstract}
The death of buzzards (Buteo buteo) found in fodder and sugar beet fields treated with granular carbofuran was investigated. To determine if there was a causal relationship between carbofuran treatment and bird mortality, earthworms of a specific fodder beet field as well as the crop contents of dead buzzards were analyzed for carbofuran contamination. Earthworms of the fodder beet field contained carbofuran concentrations up to $3.2 \mathrm{mg} / \mathrm{kg}$, while remains of earthworms and carbofuran were detected in all buzzard crop contents. The carbofuran concentrations found in the earthworms as well as in the crops of the buzzards corroborate the suspicion that the buzzards found on fodder and sugar beet fields treated with granular carbofuran had died of secondary poisoning with carbofuran via contaminated earthworms.
\end{abstract}

Wildlife die-offs in areas of intensive agricultural activity have often been observed in conjunction with the use of pesticides (Smith 1987). Indeed, most die-offs usually take place over a relatively short time-period and occur in a defined geographic area. Yet, in many instances, die-offs involve only very few animals, making it almost impossible to determine whether the animals had died of natural causes or as a consequence of a human activity, such as chemical crop protection in intensive agriculture. Furthermore, the site where the animals are found need not necessarily be identical with the location where the animals had been exposed to the xenobiotic. Unless the animals had been exposed to a lethal dose of a quickly acting toxicant, the chances are fairly high that the location where the animals are found is not identical to the location of exposure. This especially holds true for birds. In view of this situation, it is understandable that it is difficult to causally relate the use of a specific pesticide on a given field to wildlife mortality occurring simultaneously or post pesticide application in the same field. Furthermore, the high costs involved in cadaver analysis, in conjunction with the small chance of a successful identification of the causative agent, makes investigations of wildlife die-offs involving only very small numbers of animals not a very inviting and promising undertaking.

However, in some instances where recurring wildlife mortalities appear to coincide with the use of a highly toxic pesticide, it may be worthwhile to investigate a possible causal relationship between pesticide application and wildlife die-offs. Such a situation was observed in Switzerland, where raptor die-offs, usually buzzards (Buteo buteo) and red and black kites (Milvus milvus and Milvus migrans), have been occurring regularly every spring. Indeed, since 1980 a total of 90 cases, occurring in spring and involving only Buteo buteo, Milvus milvus, and Milvus migrans, were registered by the Swiss Ornithological Institute. Of these 90 birds, 50 were found dead and 40 were reported to be severely ill (Jenni-Eiermann et al. 1995). Although the individual die-offs encompassed only very small numbers of raptors per location (1-3 birds), many of these birds were found either on or in the vicinity of fields that had most recently been sown with fodder- or sugar-beet. When seeding fodder-beet, it is general agricultural practice in Switzerland to simultaneously apply carbofuran for seed protection. Carbofuran is a carbamate insecticide-nematicide ${ }^{1}$ which is usually applied at a rate of $20-30 \mathrm{~kg}$ formulation/ha i.e., $1-1.5 \mathrm{~kg}$ active ingredient/ha. Granular formulations of carbofuran have been reported to be highly toxic to wildlife and particularly to birds (Flickinger et al. 1980; Balcomb 1983; Balcomb et al. 1984a, 1984b; Mineau 1993). In general, carbamate insecticides rapidly inhibit cholinesterase's via carbamylation of the enzyme, killing the exposed animal as a result of neuromuscular and central nervous system blockage (Hill 1989). Thus, the question was asked whether the reported raptor deaths were causally related to field applications of carbofuran. Granular 
Table 1. Carbofuran concentrations determined by GC/NPD a and GC/ $\mathrm{MS}^{\mathrm{b}}$ of pooled worm samples collected during the field study at the respective sampling dates

\begin{tabular}{ll}
\hline & $\begin{array}{l}\text { Carbofuran concentration }(\mathrm{mg} / \mathrm{kg}) \\
\text { Sampling date }\end{array}$ \\
\hline 7.04 .92 & $<0.02$ \\
10.04 .92 & $($ Carbofuran applied) \\
11.04 .92 & $0.8^{\mathrm{c}}$ \\
14.04 .92 & $<0.02$ \\
15.04 .92 & $<0.02$ \\
16.04 .92 & $<0.02$ \\
21.04 .92 & $<0.02$ \\
28.04 .92 & $0.1^{\mathrm{d}}$ \\
4.05 .92 & $0.6^{\mathrm{e}}$ \\
30.07 .92 & $<0.02$ \\
\hline
\end{tabular}

${ }^{a}$ GC/NPD: Gaschromatography with nitrogen-phosphorus detection

${ }^{\mathrm{b}}$ GC/MS: Gaschromatography-Mass spectrometry

${ }^{\mathrm{c}}$ GC-MS result: $3.2 \mathrm{mg} / \mathrm{kg}$ wet weight

${ }^{\mathrm{d}} \mathrm{GC}$-MS result: $<0.16 \mathrm{mg} / \mathrm{kg}$ wet weight

${ }^{\mathrm{e}} \mathrm{GC}-\mathrm{MS}$ result: $2.7 \mathrm{mg} / \mathrm{kg}$ wet weight

carbofuran is used as an in-furrow application in conjunction with fodder and sugar beet seeding. Thus, it was not a priori clear as to how raptors could be exposed to carbofuran. However, buzzards as well as red and black kites often prey on earthworms, especially during rainy days in spring. It was therefore hypothesized that raptors could potentially be exposed to carbofuran via uptake of carbofuran-contaminated earthworms. Indeed, it was reported earlier that dead and dying earthworms were found in great numbers on the surface of a field following application of carbofuran (Kring 1969), thus making easy prey for earthworm consuming raptors.

A field study was conducted with the aim to determine the effects of carbofuran on earthworms, predominantly Lumbricus terrestris, in a fodder beet field, and to assess the resulting carbofuran content of earthworms following the application. To causally relate the latter findings to raptor die-offs, raptors found dead on fodder-beet fields treated with carbofuran, as well as earthworm samples from the corresponding fields, were analyzed for carbofuran content.

\section{Materials and Methods}

\section{Field Study}

A field, approximately 0.5 ha in size, used for growing fodder beets was chosen for studying the effects of carbofuran on earthworms. On April 10, 1992, fodder beets were sown into furrows while simultaneously applying carbofuran (5\% active ingredient) at a rate of $30 \mathrm{~kg}$ formulation per ha; thus, simulating the routine concentration of carbofuran and mode of application practiced in Switzerland. Earthworm sampling was started on April 7, 1992, three days prior to carbofuran application. All sampling dates are shown in Table 1. On sampling dates, worm (Lumbricus terrestris) samples were taken from four different locations at the edge and in the middle of the field, respectively. The sample sizes ranged between 5 to 10 worms per location. Live and dead worms located on the surface or $5 \mathrm{~cm}$ under the earthsurface were collected in separate sampling bags. All worm samples were frozen immediately after collection and kept at $-30^{\circ} \mathrm{C}$ until carbofuran analysis.

\section{Toxicity of Carbofuran to Earthworms}

Although earthworm samples from the carbofuran treated field should reveal the extent to which these worms contain carbofuran, a laboratory experiment is necessary to understand how carbofuran in the soil affects earthworms and the rate of carbofuran uptake. Thus, experiments were carried out with soils containing 3-4 earthworms (Lumbricus terrestris) and either $0,2,50$, or $100 \mathrm{ppm}(\mu \mathrm{g} / \mathrm{g})$ carbofuran. For the respective experiment, $250 \mathrm{~g}$ of relatively moist soil were mixed with $50 \mathrm{ml}$ water and $0,0.125,0.25$, or $0.5 \mathrm{~g}$. carbofran ( $5 \%$ active ingredient). These prepared soils were placed in $500 \mathrm{ml}$ plastic beakers, previously perforated to allow free exchange of air, at room temperature $\left(25^{\circ} \mathrm{C}\right)$. The viability of the worms was tested every hour by taking the worms out of the respective soils and placing them on the surface again. The experiments were terminated whenever two or more worms had died or after 24 hours. Upon the death of a worm or after termination of the experiments, worms were kept frozen at $-30^{\circ} \mathrm{C}$ until carbofuran analysis was carried out.

\section{Collection of Dead and Moribund Raptors}

Since 1980, the Swiss Ornithological Institute has registered the cases in which dead or intoxicated raptors were reported in conjunction with assumed or observed pesticide application (Jenni-Eiermann et al. 1995). In addition, questionnaires were sent out to farmers since 1988 asking them to report dead raptors as soon as they were observed. Furthermore, the farmers were asked to collect and deep-freeze these birds along with earth or earthworm samples from the corresponding fields and to send the birds and samples as quickly as possible to the Ornithological Institute. In order to facilitate registration and understanding of the particular incidents, the farmers were also asked to report the chemicals or pesticides and their respective quantities used on the field(s) where the dead raptors were found.

Since 1980, a total of 90 dead or severely ill buzzards and black and red kites have been registered each spring, i.e., during a period starting from mid-March until the beginning of June. The majority of cases, however, were consistently registered in April. Of the 50 raptors found dead, 34 (68\%) were buzzards, as were $55 \%$ of the raptors reported as possibly intoxicated (Jenni-Eiermann et al. 1995). From these cases, 8 buzzards where immediate deep freezing upon detection allowed preservation of the specimen, were selected for this study. In the latter cases, intoxication of the raptors by carbofuran appeared highly likely as indicated by the use of carbofuran on the respective finding sites. Of these buzzards, the crop content was taken for carbofuran analysis. No other organs were taken for carbofuran analyses, as the rather rapid metabolism of carbofuran previously demonstrated in the Japanese quail (Coturnix coturnix japonica) (De Lavaur et al. 1991) was assumed to prevent reliable calculation of the carbofuran dose ingested by the birds.

Cholinesterase activity determinations in the brains of these raptors were not carried out as brain cholinesterase activities were shown earlier to range from normal to slightly depressed in birds experimentally intoxicated with carbofuran (Hill 1989). Furthermore, despite the possibility of brain cholinesterase activity inhibition by carbofuran in the raptors examined, no reliable results enabling dose-effect calculations were expected due to the spontaneous decarbamylation and thus reactivation of the cholinesterase activity shown to occur rapidly intravitam and post-mortem (Hill 1989).

\section{Sample Preparation}

The procedure used for extraction and sample clean-up followed a method originally intended for analysis of carbofuran residues on salad and corn published by DFG (DFG 1991). Modifications of the method are given below. 


\section{Worm Samples:}

Single worms were weighed, homogenized in a hand blender using 20 $\mathrm{ml}$ of acetone, and left standing at room temperature for 10 minutes. Subseqently, the homogenate was filtered through a standard paperfilter. An additional $20 \mathrm{ml}$ of acetone which was used to rinse the blender was filtered through the same paper filter and added to the filtrate of the homogenate.

\section{Pooled Worm Samples:}

Anhydrous sodium sulphate was added to 9-15 worms resulting in a final weight of 30 to 50 grams. This mixture was ground to a fine powder.

\section{Buzzard Crop Content:}

The crop content of each raptor was inspected and $10 \mathrm{~g}$ thereof mixed and homogenized with a four-fold amount of anhydrous sodium sulphate.

\section{Recovery Tests}

Standard amounts of carbofuran (ICT AG, Basel, Switzerland) were submitted to the complete sample clean-up procedure: between 80 and $100 \%$ of the applied amount was recovered.

Non-contaminated worm tissue was spiked with carbofuran to 0.8 and $25 \mathrm{mg} / \mathrm{kg}$ wet weight, respectively. Analysis of the extracts revealed a $60-70 \%$ and a $50 \%$ recovery for the 25 and the $0.8 \mathrm{mg} / \mathrm{kg}$ worm, respectively.

\section{Sample Analysis}

\section{Gas Chromatography:}

A gas chromatograph HRGC 5160 Mega Series (Carlo Erba, Milan, Italy) equipped with a split/splitless injector and a nitrogen specific flame ionization detector (NPD) was used. Separation was effected on a $20 \mathrm{~m} \times 0.30 \mathrm{~mm}$ glass capillary column coated with $0.26 \mu \mathrm{m}$ of polysiloxane PS086 (Hüls America Inc.). The carrier gas was hydrogen at $40 \mathrm{kPa}$ corresponding to a linear velocity of $50 \mathrm{~cm} / \mathrm{s}$. The temperatures of the injector and the detector were set to $260^{\circ} \mathrm{C}$. One $\mu$ lof the samples dissolved in $n$-hexane or iso-octane was injected at an injector temperature of $260^{\circ} \mathrm{C}$. Injection: splitless.

Two different temperature programs were used:

Single worm analyses: Injection at $100^{\circ} \mathrm{C}$ ( $2 \mathrm{~min}$ isothermal), then $10^{\circ} \mathrm{C} / \mathrm{min}$ up to a final temperature of $220^{\circ} \mathrm{C}$. The retention time of carbofuran was $11.5 \pm 0.5 \mathrm{~min}$. All other analyses: $150^{\circ} \mathrm{C}(5 \mathrm{~min}$ isothermal), then with $10^{\circ} \mathrm{C} / \mathrm{min}$ up to $180^{\circ} \mathrm{C}$ and with $30^{\circ} \mathrm{C} / \mathrm{min}$ up to a final temperature of $240^{\circ} \mathrm{C}$. The retention time of carbofuran was $9.5 \pm 0.5 \mathrm{~min}$

An integrator SP 4290 (Spectra-Physics) was used for quantification which was based on peak heights (linear in the range $0-50 \mathrm{ng}$ ). The detection limit was approximately $0.5 \mathrm{ng}$ of carbofuran. Standard solutions of $5 \mathrm{ng}, 10 \mathrm{ng}$, and $25 \mathrm{ng} / \mu \mathrm{l} n$-hexane were used. Reference carbofuran ( $98 \%$ purity) was received from ICT AG, Basel, Switzerland.

\section{Gas Chromatography/Mass Spectrometry (GC/MS):}

GC conditions were as indicated above. The interface between the gas chromatograph and the mass spectrometer was a $0.15 \mathrm{~mm}$ i.d. persilylated piece of fused silica tubing held at $280^{\circ} \mathrm{C}$. Two different mass
Table 2. Carbofuran content in single worms in comparison to their location in the soil, viability, and sampling date (concentrations on wet weight basis)

\begin{tabular}{|c|c|c|c|c|}
\hline Date & $\begin{array}{l}\text { Worm } \\
\text { no. }\end{array}$ & Location & Viability & $\begin{array}{l}\text { CF concentration } \\
\text { (mg/kg) } \\
\text { GC/NPD }\end{array}$ \\
\hline 28.4 .92 & 1 & b.s. & alive & $\leqslant 0.80$ \\
\hline 24.4 .92 & 2 & b.s. & alive & $\leqslant 0.20$ \\
\hline 04.5 .92 & 1 & b.s. & alive & $\leqslant 0.20$ \\
\hline 04.5 .92 & 2 & b.s. & alive & $\leqslant 0.20$ \\
\hline 04.5 .92 & 3 & b.s. & alive & $\leqslant 0.03$ \\
\hline 04.5 .92 & 4 & b.s. & alive & $\leqslant 0.06$ \\
\hline 04.5 .92 & 5 & b.s. & alive & $\leqslant 0.05$ \\
\hline 04.5 .92 & 6 & b.s. & alive & $\leqslant 0.09$ \\
\hline 04.5 .92 & 7 & b.s. & alive & $\leqslant 0.10$ \\
\hline 04.5 .92 & 8 & b.s. & alive & $\leqslant 0.03$ \\
\hline 04.5 .92 & 9 & b.s. & dead & $\leqslant 2.00^{\mathrm{a}}$ \\
\hline 04.5 .92 & 10 & b.s. & dead & $\leqslant 2.00^{b}$ \\
\hline 04.5 .92 & 11 & o.s. & alive & $0.30^{\mathrm{c}}$ \\
\hline 04.5 .92 & 12 & o.s. & alive & $\leqslant 0.10$ \\
\hline
\end{tabular}

b.s.: $5 \mathrm{~cm}$ below the soil surface

o.s.: on the soil surface

${ }^{\mathrm{a}} \mathrm{GC}-\mathrm{MS}$ result: $2.4 \mathrm{mg} / \mathrm{kg}$ wet weight

${ }^{\mathrm{b}} \mathrm{GC}$-MS result: $0.6 \mathrm{mg} / \mathrm{kg}$ wet weight

${ }^{\mathrm{c}} \mathrm{GC}-\mathrm{MS}$ result: $0.8 \mathrm{mg} / \mathrm{kg}$ wet weight

spectrometers were used: a quadrupole instrument mod. 4510 (Finnigan, Sunnyvale, CA, USA) was run in electron impact ionization mode ( $82 \mathrm{eV}$ electron energy), while the temperature of the ion source was held at $190^{\circ} \mathrm{C}$. Mass spectra were recorded between $\mathrm{m} / \mathrm{e} 41$ and $\mathrm{m} / \mathrm{e}$ 400 ( 1 sec. cycle time). The second instrument was a double focusing magnetic sector mass spectrometer Finnigan MAT 95 in electron impact mode at $70 \mathrm{eV}$ with a mass resolution of 1000 . Scan range was from $\mathrm{m} / \mathrm{e} 33$ to 350 with a cycle time of $1.226 \mathrm{sec}$. The temperature of the ion source was set to $260^{\circ} \mathrm{C}$

The mass spectrum of reference carbofuran shows the molecular ion at $\mathrm{m} / \mathrm{e} 221$ with a relative intensity of $1.4 \%$. The base peak at $\mathrm{m} / \mathrm{e} 164$ is due to cleavage of methyl isocyanate. Other typical fragments are observed at $\mathrm{m} / \mathrm{e} 122,131$, and 149 with $14 \%, 14 \%$, and $53 \%$ relative intensity, respectively. The quantitative determination of carbofuran was based on the signal areas in the mass chromatograms of $\mathrm{m} / \mathrm{e} 149$ and 164 . The sums of these areas were compared with the respective data of a carbofuran reference (external standard).

\section{Results}

The application of granular carbofuran to a field resulted in an initially high amount of carbofuran $(3.2 \mathrm{mg} / \mathrm{kg})$ in the pooled earthworm samples (Table 1). Although the earth was quite damp at this time point, the granules were still intact. The subsequent 17 days were characterized by very dry weather and by no change in the appearance of the carbofuran granules. No carbofuran was detectable in earthworm samples taken within these days (detection limit $0.02 \mathrm{mg} / \mathrm{kg}$ ). However, as of April 28 , it started to rain and the granules commenced to dissolve. On the 4th of May, carbofuran concentrations of $2.7 \mathrm{mg} / \mathrm{kg}$ were detectable in the pooled worm samples (Table 1), while the single worm analyses demonstrated a high variability in carbofuran concentrations ranging from below the detection limit up to $2.4 \mathrm{mg} / \mathrm{kg}$ (Table 2). Interestingly, even at the relatively high carbofuran concentration of $0.8 \mathrm{mg} / \mathrm{kg}$, the 
Table 3. Carbofuran concentrations in the earthworms of a laboratory experiment with earthworms exposed to soil contaminated with granular carbofuran, as applied in the field situation (concentrations on wet weight basis)

\begin{tabular}{llll}
\hline $\begin{array}{l}\text { Carbofuran } \\
\text { in soil } \\
(\mathrm{mg} / \mathrm{kg})\end{array}$ & $\begin{array}{l}\text { Worms } \\
\mathrm{n}\end{array}$ & $\begin{array}{l}\text { Time 100\% } \\
\text { moribund } \\
\text { (h) }\end{array}$ & $\begin{array}{l}\text { Carbofuran } \\
\text { in earthworms } \\
(\mathrm{mg} / \mathrm{kg})\end{array}$ \\
\hline 0 & 3 & - & $<0.02$ \\
25 & 4 & $>24^{\mathrm{a}}$ & $4.2 \pm 1.1$ \\
50 & 3 & 24 & $21.3 \pm 5.1$ \\
100 & 3 & 6 & $16.6 \pm 2.2$ \\
\hline
\end{tabular}

${ }^{\text {a }}$ Only 2 of 4 earthworms died within 24 h of carbofuran exposure

earthworms showed no overt effects of intoxication. Comparable amounts of carbofuran were found in earthworms collected at the surface or $5 \mathrm{~cm}$ below the surface. Due to the presence of many interfering signals at the retention time of carbofuran, no reliable identification and quantification was possible based on GC/NPD results, thus allowing the calculation of an upper limit only (Table 2 ).

The laboratory studies with carbofuran showed that carbofuran at concentrations of 25,50 , and $100 \mathrm{mg} / \mathrm{kg}$ earth was acutely toxic to earthworms and led to a high uptake of carbofuran (Table 3). All of the exposed earthworms showed edemalike lesions. As already observed in the field experiments, worms with relatively high carbofuran concentrations were found at or close to the surface, indicating that highly contaminated worms would be available for potential predators.

The mass spectra of all field samples taken at the retention time of carbofuran exhibited a signal at m/e 178, overlapping the spectrum of the pure carbofuran which proved to be the molecular ion of anthracene. Co-chromatography with original anthracene confirmed co-elution with carbofuran. The origin of anthracene is not yet known. It does not seem to be related to the application of carbofuran, since it was not detectable in the original carbofuran formulation applied to the field. Of the eight buzzards (Buteo buteo) inspected for carbofuran intoxication, five had partially filled crops containing mostly earthworms, while the crops of the remaining three birds were virtually empty. Upon gross inspection, all of the birds appeared to have been in good physical condition. Indeed, the average weight $(0.87 \pm 0.12 \mathrm{~kg})$ of these birds compares quite well with literature values reported for healthy buzzards (Glutz von Blotzheim 1971). Subsequent GC/MS analyses of the crop contents revealed the presence of carbofuran in all of the crop samples, the amounts ranging between 3 and $1100 \mu \mathrm{g}$ carbofuran per crop (Table 4).

To test the reliability of the carbofuran concentration determinations in crop content, a second determination was carried out with three of the crop samples. The comparison of the respective results (Table 4) demonstrates remarkable differences between repetitive determinations. These differences can be attributed to unsatisfactory efficiency of the sample clean-up steps. The incomplete removal of material from the sample superimposing the chromatographic signal of carbofuran (Figure 1) precluded a quantitative analysis by GC/NPD. Therefore, GC/MS had to be used. Due to the lack of a suitable internal standard for GC/MS analysis, the quantitative evaluation had to be based on external standardization, resulting in a reduced reproducibility of the quantitative data.
Table 4. Carbofuran determined by $\mathrm{GC} / \mathrm{NPD}^{\mathrm{a}}$ and $\mathrm{GC} / \mathrm{MS}^{\mathrm{b}}$ in crop contents of buzzards (Buteo buteo) found dead or dying on carbofuran treated fields (concentrations on wet weight basis)

\begin{tabular}{lccll}
\hline & \multicolumn{2}{l}{$\begin{array}{l}\text { CF concentration } \\
\text { in crop content }(\mathrm{mg} / \mathrm{kg})\end{array}$} & & $\begin{array}{l}\text { CF amount in } \\
\text { crop }(\mathrm{mg})\end{array}$ \\
\cline { 2 - 3 } $\begin{array}{lccl}\text { Buzzard } \\
\text { No. }\end{array}$ & GC/NPD & GC/MS & & GC/MS \\
\hline 1 & $\leqslant 20$ & 15 & 0.300 \\
$1^{*}$ & $\leqslant 11$ & 3.8 & 0.084 \\
2 & $\leqslant 12$ & 7.0 & 0.063 \\
3 & $\leqslant 7.0$ & 7.0 & 0.364 \\
$3^{*}$ & $\leqslant 5.1$ & 21 & 1.092 \\
4 & $\leqslant 1.2$ & 2.5 & 0.012 \\
$4^{*}$ & $\leqslant 0.5$ & 0.6 & 0.003 \\
5 & $\leqslant 1.4$ & 1.6 & 0.005 \\
6 & $\leqslant 1.6$ & 2.0 & 0.040 \\
7 & $\leqslant 105$ & 38 & 0.874 \\
8 & $\leqslant 34$ & 25 & 0.368 \\
\hline
\end{tabular}

*Repetitive extraction and determination

${ }^{a}$ GC/NPD: Gaschromatography with nitrogen-phosphorus detection

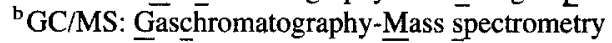

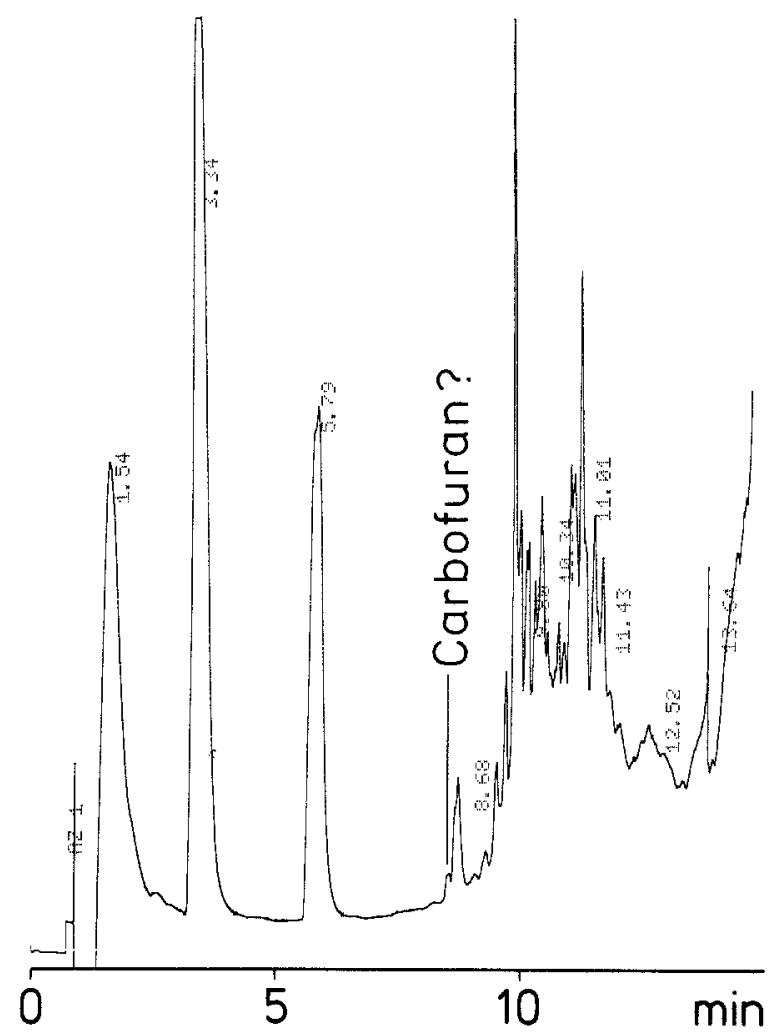

Fig. 1. Gas chromatogram of an extract of buzzard crop content recorded via nitrogen-phosphorus selective flame ionization detection (Sample no. 4, Table 4)

\section{Discussion}

All of the buzzards found dead in conjunction with carbofuran application in agriculture clearly were exposed to carbofuran, as demonstrated by the presence of carbofuran in the crop contents of these birds. The question, however, remained as to 
how these birds were exposed and whether the amounts of carbofuran that were ingested would be sufficient to be acutely lethal.

The field survey demonstrated that carbofuran-exposed earthworms contained carbofuran concentrations ranging between $<0.02 \mathrm{mg} / \mathrm{kg}$ and $3.2 \mathrm{mg} / \mathrm{kg}$. A simulation of the field situation in the laboratory with soil concentrations of 25-100 ppm carbofuran resulted in earthworm carbofuran concentrations plateauing at $15-20 \mathrm{mg} / \mathrm{kg}$ earthworm. This lethal body burden for earthworms is a result of the initial carbofuran concentration in the earth and the duration of the exposure, i.e., time between the beginning of carbofuran exposure until the earthworm had died. Indeed, the highest soil carbofuran concentration of $100 \mathrm{ppm}$ resulted in $100 \%$ mortality within $6 \mathrm{~h}$ and an earthworm concentration of 17 ppm carbofuran, while conversely a medium soil carbofuran concentration of $50 \mathrm{ppm}$ resulted in $100 \%$ mortality within $24 \mathrm{~h}$ and an earthworm concentration of $21 \mathrm{ppm}$ carbofuran. The toxic effects of carbofuran to earthworms observed during the laboratory experiments with earthworms were not unexpected, as carbofuran was shown to be a formidable lumbricide in the late $1960 \mathrm{~s}$ (Kring 1969). An approximate calculation of the soil carbofuran concentrations achieved after field application, based on a furrow radius of $3 \mathrm{~cm}$, a furrow length of $10,000 \mathrm{~cm}, 500$ furrows per ha, a weight of $1 \mathrm{~kg} / 1,000 \mathrm{~cm}^{3}$ earth, and a field application dose of $1.5 \mathrm{~kg}$ carbofuran active ingredient per ha, would result in an average concentration of $10.6 \mathrm{ppm}$ carbofuran in the soil, i.e., about 2.5 to 10 -fold lower than the concentrations employed in the laboratory experiments.

The field observation that buzzards often scavenge on earthworms and the presence of earthworms in the crops of the dead buzzards analyzed suggests that these birds were exposed to carbofuran via carbofuran-contaminated earthworms. However, the carbofuran concentrations in the earthworms collected from the treated field were lower than the concentrations found in the buzzard crops. This suggests that earthworms contaminated with carbofuran are not the sole route of carbofuran exposure in these raptors. It is possible that a small number of undissolved carbofuran granules were either taken up by the raptors via earth or adhered to earthworms when feeding on earthworms. When calculating with an average food intake of $0.1 \mathrm{~kg}$ per buzzard per day and a mean earthworm contamination with carbofuran of $2 \mathrm{mg} / \mathrm{kg}$ earthworm, buzzards could be exposed to approximately $0.2 \mathrm{mg}$ carbofuran $/ \mathrm{kg}$ body weight.

Although species-specific data on the toxicity of carbofuran to buzzards is not available, studies with other birds of prey such as eastern screech owls (Otus asio) and American kestrels (Falco sparverius) reported $\mathrm{LD}_{50} \mathrm{~s}$ for carbofuran of $1.9 \mathrm{mg} / \mathrm{kg}$ and $0.6 \mathrm{mg} / \mathrm{kg}$, respectively (Wiemeyer and Sparling 1991). Thus, assuming that buzzards have a similar susceptibility for carbofuran as American kestrels, the carbofuran concentrations detected in the crops of the buzzards analyzed were in the lethal range. On the other hand, the presence of carbofuran in the crop contents of these buzzards does not prove that the birds had died of a carbofuran intoxication since this material has obviously not yet been absorbed. However, the contents of the crop are representative for the type of food ingested by these birds at the respective locations shortly before death. Furthermore, in two of the cases, the symptoms observed before death, such as muscle spasms, laborious breathing, emesis, and partial paralysis, compare well with symptoms of birds intoxicated with cholinesterase inhibitors (Balcomb 1983; Rattner and Franson 1984; Wiemeyer and Sparling 1991; Mineau 1993).

The results presented above regarding the likelihood of secondary poisoning of buzzards with carbofuran via prey species corroborate earlier reports by Balcomb (1983). In the latter study, red shouldered hawks (Buteo lineatus) were reported to have fed on American robins (Turdus migratorius) contaminated with granular carbofuran. The concentrations of carbofuran found in the gastrointestinal tract of the intoxicated hawks amounted to approximately $10 \%$ of the $\mathrm{LD}_{50}$ of carbofuran in American kestrels.

Although 90 cases of suspected raptor intoxications have been reported during spring periods in Switzerland since 1980, causality to intoxication with carbofuran was established only for the 8 cases presented here. It is feasible to assume that the number of raptors intoxicated with carbofuran is higher. However, the elusive behavior of raptors as well as the poor documentation in conjunction with reported raptor deaths preclude a better assessment of the number of affected raptors. As a consequence of the mechanism of action, the intoxication with carbofuran is primarily an acute event occurring specifically only during a very short period in the spring shortly after fodder and sugar beets are sown or following massive dissolution of the granules after heavy rainfall. Since this period coincides with the breeding period of buzzards and kites (Glutz von Blotzheim $1964,1971)$, it can be assumed that chicks of these raptors could be exposed to acutely toxic concentrations of carbofuran, but only in cases where the adult bird itself has already been exposed to high concentrations of this compound. This would mean that while theoretically in single cases a whole family of buzzards or kites could fall victim to acute carbofuran poisoning, the population of raptors as a whole, however, is not endangered. Indeed, observations by the Swiss Ornithological Institute do not show declines in either the buzzard nor the kite populations during the last 5-10 years (N. Zbinden, personal communication). In addition, near-lethal intoxication with cholinesterase inhibitors could have an effect on the ability of raptors to catch prey and thus on their ability to provide enough food for their brood. It was shown earlier that high dose levels of carbamate and organophosphate insecticides interfere with the thermoregulatory ability of birds and thus essentially with their fitness for survival (Rattner and Franson 1984; Fleming et al. 1985; Maguire and Williams 1987; Rattner et al. 1987; Martin and Solomon 1991; Martin and Forsyth 1993). Cold stress especially increased the mortality of carbamate or organophosphate intoxicated birds and their brood (Rattner and Franson 1984; Maguire and Williams 1987; Rattner et al. 1987; Martin and Solomon 1991); this occurred, however, only when the birds were intoxicated with cholinesterase inhibitor concentrations near the acutely lethal levels.

In summary, the data presented here indicate that the field application of granular carbofuran can result in copious concentrations of carbofuran in earthworms, however, only immediately after application or following increased dissolution of the granular form during rainy periods. In such situations, earthworms contaminated with carbofuran can provide a basis for secondary poisonings of birds of prey, specifically buzzards and red and black kites.

Acknowledgments. This study was funded in part by a grant from the Swiss Environmental Protection Agency (BUWAL). 


\section{References}

Balcomb R (1983) Secondary poisoning of red-shouldered hawks with carbofuran. J Wildl Manage 47(4):1129-1132

Balcomb R, Bowen CA, Wright D, Law M (1984a) Effects on wildlife of AT-planting corn applications of granular carbofuran. J Wildl Manage 48(4):1353-1359

Balcomb R, Stevens R, Bowen CA (1984b). Toxicity of 16 granular insecticides to wild-caught songbirds. Bull Environ Contam Toxicol 33:302-307

De Lavaur E, Carpentier-Le Sech J, Prin AM (1991) Etude de la distribution et de la persistance post mortem du carbofuran chez la caille japonaise (Coturnix coturnix japonica). Gibier Faune Sauvage $8(3): 65-77$

Deutsche Forschungs Gemeinschaft (1991) Carbosulfan, Carbofuran. Rückstands-analytik von Pflanzenschutzmitteln. Verlag Chemie $\mathrm{mbH}$. 658(344)1-658(344)14

Fleming WJ, Heinz GH, Franson JC, Rattner BA (1985) Toxicity of Abate ${ }^{\circledR} 4 \mathrm{E}$ (temephos) in mallard ducklings and the influence of cold. Environ Toxicol Chem 4:193-199

Flickinger EL, King KA, Stout WF, Mohn MM (1980) Wildlife hazards from Furadan 3G applications to rice in Texas. J Wildl Manage 44(1):190-197

Glutz von Blotzheim UN (1964) Die Brutvögel der Schweiz. Verlag Aargauer Tagblatt AG, Aarau, Switzerland (1971) Handbuch der Vögel Mitteleuropas. Akademische Verlagsgesellschaft, Frankfurt am Main, FRG

Hill EF (1989) Divergent effects of postmortem ambient temperature on organophosphorus- and carbamate-inhibited brain cholinesterase activity in birds. Pesticide Biochem Physiol 33:264-275

Jenni-Eiermann S, Bachmann H, Zbinden N, Dietrich DR (1995)
Greifvogel Mortalität im Zusammenhang mit der Applikation von Pfalnzenschultzmitteln im Frühling. Ornitholog. Beobachter in preparation

Kring JB (1969) Mortality of the earthworm Lumbricus terrestris L. following soil applications of insecticides to a tobacco field. J Econ Entomol 62:963

Maguire CC, Williams BA (1987) Cold stress and acute organophosphorus exposure: Interaction effects on juvenile Northern Bobwhite. Arch Environ Contam Toxicol 16:477-481

Martin PA, Forsyth DJ (1993) Survival and behaviour of captive mallard broods exposed to carbofuran-sprayed vegetation: A field experiment. Ecotoxicol 2:79-92

Martin PA, Solomon KR (1991) Acute carbofuran exposure and cold stress: Interactive effects in mallard ducklings. Pesticide Biochem Physiol 40:117-127

Mineau P (1993) The hazard of carbofuran to birds and other vertebrate wildlife. Can Wildlife Service, Technical Report Series No. 177, ISBN 0-662-20823-4, Ottawa, Canada

Rattner BA, Becker JM, Nakatsugawa T (1987) Enhancement of parathion toxicity to quail by heat and cold exposure. Pesticide Biochem Physiol 27:330-339

Rattner BA, Franson JC (1984) Methyl parathion and fenvalerate toxicity in American kestrels: Acute physiological responses and effects of cold. Can J Physiol Pharmacol 62:787-792

Smith GJ (1987) Pesticide use and toxicology in relation to wildlife: Organophosphorus and carbamate compounds. US Fish and Wildlife Service, Resource Publication 170, Washington DC, USA

Wiemeyer SN, Sparling DW (1991) Acute toxicity of four acetylcholinesterase insecticides to American kestrels, eastern screechowls and northern bobwhites. Environ Toxicol Chem 10:11391148 